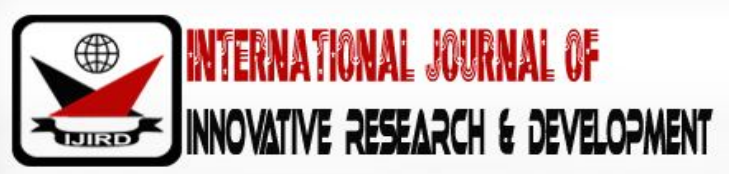

ISSN 2278 - 0211 (Online)

\section{Investigating Pre-Service Science Teachers' Science Knowledge Level at the Colleges of Education in Ghana}

\begin{tabular}{c} 
Nathan Ohene Gyang \\
Tutor, Department of Science, Akrokeri College of Education, Akrokeri, Ghana \\
Charles Agyei Amoah \\
Tutor, Department of Science, OLA College of Education, Cape Coast, Ghana \\
Akorfa Akosua Agbosu \\
Tutor, Department of Science, Akrokeri College of Education, Akrokeri-Ghana \\
\hline
\end{tabular}

\begin{abstract}
:
The study investigated pre-service basic teachers' science knowledge level to determine their content knowledge in science.Cluster sampling was used to select the sample size of 200 pre-service basic school science teachers from five colleges of education in Ashanti and Central Regions of Ghana. The Integrated Science Achievement Test (ISAT) consisting of 24 multiple choice items made up of biology, physics, and chemistry topics was designed to measure science knowledge level of pre-service basic school science teachers. The result indicated that pre-service basic science teachers have a little above average science content knowledge. It is recommended that pedagogical content knowledge (PCK) in science should be part of the curriculum of Colleges of Education in Ghana as a course and much emphasis placed on acquisition of science content knowledge.
\end{abstract}

Keywords: Science knowledge level, pedagogical content knowledge

\section{Introduction}

The issue of teacher subject knowledge continues to attract attention from educators and those responsible for funding professional development of teachers. Augus, Olney, Calwell, Burke and Seleck (2004) revealed that many basic school teachers lack confidence to teach science such that it is one of the least taught subjects in the basic school curriculum, due to the inadequate science content knowledge of pre-service basic school teachers. Lack of science content knowledge is often cited as the cause of teachers' inability to teach science effectively (Fleer, 2009) and it can lead their students to

misconceptions (Kaptan \& Korkmaz, 2001). V Variations in teachers' science understanding have been identified as the main factor responsible for the differences in the quality of elementary science teaching (Shallcross, Spink, Stephenson, \& Warwick, 2002). According to Ball \& Bass (2000) a teacher will not have the ability to respond to the needs of students without good subject matter knowledge. Morgan (2012) asserted that many teachers feel that they are not competent enough to be science literate and good science teachers. Goulding, Rowland, and Barber (2002) found that a positive correlation existed between an audited level of subject knowledge and the level of teaching performance of the pre-service teachers' as determined through observation of their teaching. According to them a higher level of subject knowledge resulted in a higher probability of a higher level of teaching performance, and a lower level of subject matter knowledge gave a higher probability of a lower level of teaching performance.

Furthermore, Tekkaya, Çakıroğlu, \&Özkan (2002) investigated Turkish pre-service science teachers' understanding of science concepts, attitude toward science teaching and their efficacy beliefs regarding science teaching. Findings of the study indicated that majority of the participants had misconceptions concerning fundamental science concepts. Stevens \&Wenner (1996) found weak knowledge base in science and mathematics amongst pre-service teachers in their assessment of both content knowledge and beliefs. They suggested that pre-service teachers' may well need further background in science presented at a level that connects with their current conceptual level and extends this in ways that might be meaningful for them as they enter a career in education.

Teaching practice in the Colleges of Education in Ghana is a critical aspect of teacher development. This is always preceded by an on-campus teaching practice period, during which trainees are sent through the rudiments of teaching as the development of science pedagogical content knowledgeis important to their professional training. The experiences gained during the aforementioned activities indicate that it takes quite some time to develop their subject matter knowledge. It is not 
clear how much science content knowledge the trainees have mastered in their development in the various stages of their teacher education. This study has therefore, been, designed to capture the extent of development of science content knowledge by trainees who are in their second year of the three-year training program.

\section{Statement of the problem}

Some pre-service basic school science teachers exhibit low level of conceptual and factual knowledge as well as inadequate skills in the content area of science. This was revealed through supervision and observation during on-campus and off-campus teaching practice of some teacher trainees. Inadequate science content knowledge significantly contributes to basic school teacher's hesitancy, and possible inability to provide effective science instruction in their classrooms (Sarikaya, 2004).Tekkaya, Çakıroğlu and Özkan (2002) investigated Turkish pre-service science teachers' understanding of science concepts and found out that majority of the participants had misconceptions concerning fundamental science concepts.Other studies on trainees' science knowledge level found a low level of conceptual and factual science knowledge as well as inadequate skills in the content area of science amongst pre-service teachers' (Wenner, 1995).

This study is therefore designed to investigate the science knowledge level of teacher trainees undergoing science teacher education in some Colleges of Education in Ghana so as to determine their preparedness for teaching in the future.

\section{Purpose of the study}

The purpose of the study is to investigate pre-service basic science teachers' science knowledge level to determine their content knowledge of the basic level science syllabus.

\subsection{Research Question}

- What knowledge level do pre-service science teachers in Colleges of Education have towards science teaching in basic schools?

\section{Methodology}

Descriptive survey design was used in this study. The target population chosen was second year pre-service teachers' in Colleges of Education in Ghana because of their common binding characteristics or traits.Cluster sampling was done to select 200 pre-service science teachers from 38 public colleges of education in Ghana. Five colleges from Ashanti and Central region of Ghana were randomly selected with each providing 40 students.

The Integrated Science Achievement Test (ISAT) was designed to measure science knowledge level of pre-service elementary teachers'. It consisted of 24 multiple choice items made up of biology, physics, and chemistry topics. The instrument was subjected to reliability and validity.

\section{Findings}

\subsection{Science Knowledge Level of the Pre-service Teachers}

The instrument that tested the Integrated Science content knowledge (ISCK) of the pre-service teachers comprised 24 items based on the College of Education science syllabus. The marks obtained by pre-service teachers from each college were aggregated and the mean marks, percentages and the standard deviation determined. The results are presented in Table 1. The data arranged in descending order of highest mean score to the lowest mean score.

\begin{tabular}{|c|c|c|c|}
\hline Institutions & Mean mark & Percentage (\%) & Standard deviation \\
\hline College B & 16.55 & 51.38 & 4.958 \\
\hline College C & 12.45 & 69.38 & 2.952 \\
\hline College A & 12.33 & 51.88 & 5.972 \\
\hline College D & 11.32 & 47.17 & 3.778 \\
\hline College E & 11.18 & 46.58 & 3.665 \\
\hline \multicolumn{2}{|l}{ Table 1: Analysis of Pre-Service Teachers' Test Scores on ISAT } \\
\hline
\end{tabular}

Pre-service teachers' in college B obtained the highest mean marks with the least spread marks about the mean. The next highest mean mark was obtained from college $\mathrm{C}$, which had the widest spread of marks about the mean mark. The least mark was obtained from college E, which had a medium spread of marks about the mean mark. In this study, it was expected that the performance in each college would be above the $50 \%$ mean mark. It is seen from the data in Table 1 that colleges D and E obtained mean marks below the 50\% mean mark. This resulted is not consistent with the study conducted byTekkaya, Çakıroğlu and Özkan (2002) who investigated Turkish pre-service science teachers' understanding of science concepts and found out that majority of the participants had misconceptions concerning fundamental science concepts.Other studies on trainees' science knowledge level found a low level of conceptual and factual science knowledge as well as inadequate skills in the content area of science amongst pre-service teachers' (Wenner, 1995).

In order to present the results of the achievement test for the colleges in a pictorial form, 


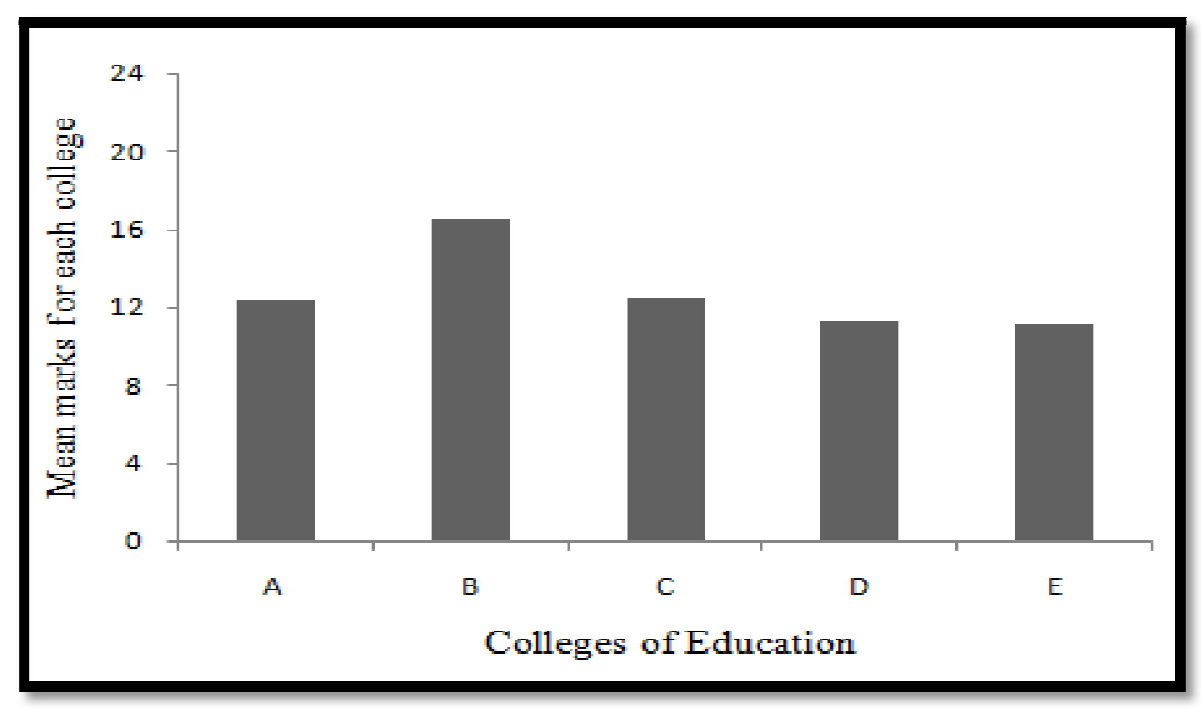

Figure 1: A Bar Chart Showing Science Knowledge Level for Each College

\section{Conclusion}

Analysis of the Integrated Science Achievement Test revealed that pre-service basic science teachers have a little above average science content knowledge. It is recommended that pedagogical content knowledge (PCK) in science should be part of the curriculum of Colleges of Education in Ghana as a courseandmuch emphasis placed on acquisition of science content knowledge to improve theconceptual knowledge level in science of preservice teachers.

\section{Reference}

i. Angus, M., Olney, H., Calwell, B., Burke, G., Seleck, R. (2004). The sufficiency of resources for Australian primary schools. Canberra: DESTo.

ii. Ball, D. L., \& Bass, H. (2000). Interweaving content and pedagogy in teaching and learning to teach: Knowing and using mathematics. In J. Boaler (Ed.), Multiple perspectives on mathematics teaching and learning (pp. 83-104). Westport, CT: Ablex Publishing.

iii. Goulding, M., Rowland, T. \& Barber, P. (2002,) 'Does it matter?Primary Teacher trainees' subject knowledge in mathematics'. Special Issue of the British Educational Research Journal on Subject Matter Knowledge and Application

iv. Fleer, M. (2009). Supporting scientific conceptual consciousness or learning in 'a roundabout way' in play-based contexts. International Journal of Science Education, 31(8), 1069-1089.

v. Kaptan, F. \& Korkmaz, H. (2001). Primary school preservice teachers' misconceptions about heat and temperature in science teaching. Hacettepe University Journal of Education, 21, 59-65.

vi. Morgan, A. (2012). 'Me as a Science Teacher': Responding to a Small Network Survey to Assist Teachers with SubjectSpecific Literacy Demands in the Middle Years of Schooling. Australian Journal of Teacher Education, 37 (6).

vii. Sarikaya, H. (2004). Pre-service elementary teachers' science knowledge, attitude toward science Teaching and their efficacy belief regarding science teaching. Unpublished master's thesis, Middle East Technical University, Ankara, Turkey.

viii. Shallcross, T., Spink, E., Stephenson, P. \& Warwick, P. (2002). How primary trainee teachers perceive the development of their own scientific knowledge: Links between confidence, content and competence? International Journal of Science Education, 24(12), 1293-1312.

ix. Stevens, C., \& Wenner, G. J. (1996). Elementary pre-service teachers' knowledge and beliefs regarding science and mathematics. School Science and Mathematics, 96(1), 2-9.

x. Tekkaya, C., Çakıroğlu, J., Özkan, Ö. (2002). A case study on science teacher trainees. Teaching: International Research and Pedagogy, 30(1), 57-66.

xi. Trumper, R. (2001). A cross-age study of junior high school students' conceptions of basic astronomy concepts. International Journal of Science Education, 23, 1111-1124.

xii. Wenner, G. (1995). Science knowledge and efficacy beliefs among pre-service elementary teachers: A follow- up study. Journal of Science Education and Technology, 4(4), 307-315. 